\title{
The Application of Experiential Marketing in China's Real Estate
}

\author{
Zheyu Zhao \\ College of Industrial \& Commercial Management, Tianjin Polytechnic University \\ Tianjin 300387, China \\ E-mail: zhaozheyu874361@126.com \\ Chunying Zhang \\ College of Industrial \& Commercial Management, Tianjin Polytechnic University \\ Tianjin 300387, China \\ E-mail: zhchy169@163.com
}

\begin{abstract}
This paper discusses Experiential Marketing as a new marketing model of a new era of economic, is necessary to be used in the real estate marketing, and propose that in real estate marketing processes works such as positioning, experiencing, surround ings and other aspects should be done well. We can conclude that in order to make the experiencing marketing become an important link in the process of improve the customer satisfaction and the brand loyalty.
\end{abstract}

Keywords: Experiential economy, Experiential marketing, Real estate marketing

\section{Introduction}

In recent years, with the rapid development of China's national economy and the house system reform, real estate has made great development, real estate market gradually improve, consumers become more mature and rational. With the increased competition, Real estate exploitation enterprises have more and more attention to marketing. Experience marketing is accompanied by the emergence of this trend, which can meet the psychological needs of consumers and communicate to consumers more effectively. It becomes a real estate marketing trend.

\section{Experiential Marketing and Experiential Marketing in real estate}

\subsection{Experiential Economy}

In recent years, the "Experiential Economy" as a unique economic phenomenon, has become the world's first cutting-edge business topics. Experiential Economy is characterized by: The consumption is only a process. At the end of the process, the memory of experience will be preserved in the minds of consumers permanently. As early as the 1970s, the American futurist Alvin - Toffler proposed the viewpoint that "Service industry will surpass the manufacturing industry eventually, and the experience production will also surpass service industry". The Economists Payne pointed out that: "The so-called experience, in essence refers to pasting a period of time in a personal way, a series of events that can be recalled from the process of the experience." economic offering will be divided into universal merchandise, general merchandise, services and experience and so on. In their view, experience is the forth- economic offering.Today,the economies of scale, which due to the large-scale production of products and services, led to the corresponding cost savings , low-cost competitive of products and value-added services difficulty. Extract the experience from the goods and services, which has opened up extraordinary new ways to expand the economy.

\subsection{Experiential Marketing}

Experiential Marketing is the operator standing on consumer's point of view of consumers to experience the concept of the purchase, proccess of the purchase, thoughts of purchase and driving force of the purchase, that is, from a consumer's senses, feelings, thinking, action and connection this five aspects to define and design of the way of thinking about marketing. Experiential Marketing has changed the past concept that only stressing "clients" or "customer service" manner. It advocates the experience, enables customers to experience and become directly involved as the main body, creating a kind of "feeling that will not forget" satisfy there needs mentally to the greatest extent in order to win customer trust and loyalty so that to promote product sales. Experiential Marketing breaking the assumption of the "rational 
consumer" and believe that the consumer have both Sense and Sensibility, and consumers'experience in the pre-sale, sale, after-sale are the key to study the behavior of consumers and how to manage the brand of a competation.

\subsection{Experiential Marketing in real estate}

Experiential Marketing in real estate is an integrated marketing and managing system, including every segment of the process from product design to marketing. Buyers are the centre of which this methods of the whole process is designed, it is necessary to consider the feeling when the buyers see it, hear it, use it, even more concerning about the buyers in house experience should be fresh and multiple ,also can see and feel themselves better than their imagination, this is the real Experiential Marketing.

\section{Experiential Marketing is an inevitable trend in real estate marketing}

\subsection{Real estate and "experience" are inseparable}

Real estate and architecture are connected inextricably, at first architecture was a of aesthetics, and the center of the study of aesthetics is "experience" and even "aesthetic" the word itself means experience.

Real estate developers and real estate service providers should build a strong customer resources, access to high-value customer's personal preferences, and offer experience and improve the environment for the purchase basing on customers'hobbies to guide them to participate in order to set Unforgettable impression.

\subsection{Experiential Marketing is the momentum of real estate's development}

People's perception of things being multiple requires the enterprises no longer meet their need of performance of the house and price only, a number of "living" associated experience, such as food, clothing, transportation all became buyers' lifelong perceptions of the to be considered.

Fragmental requirements begin to make customers concerning about the details of their everyday life, but these details are usually hard to be considered during the time they were giving advertisement.So the most effective way for the real estate industry is to let the customer to have experience in the houses, to taste the food, wear their clothes, live, all the services, so that enterprises can get the most detailed and most market fitted feedback, through which they can organize the designation, development and operating activities. Direct requirements of the market means companies can not only rely on media ,a wonderful experience is the most persuasive; At the same time, cultures of the companies, lifestyle, and other abstract things which were used as imagination before for business purposes, now may also be offered to customers to integrate into their lives and be percepted directly.

\subsection{Experiential Marketing can make up for deficiencies of the existing marketing model}

Experiencial marketing is an important change of the sales models,.on the one hand, from the very beginning it is integrated with the market since the investment and the designation of real estate. The starting point is to create an atmosphere that can experienced by comprehensive customers, so that is conducive to fully catch with the market, and eliminate of much of bad facts created by marketing subjectively and thinking in one-sided in the past. On the other hand, the demands of the customer experience of marketing real estate is not just function, the environment, the price, they are selling lifestyle and value system, they constantly bring surprises into the experiences to show them unique lifestyles, according to the same time, at the same time according to some of the special requirements they design the entire personal service.

Finally, the key is to create an atmosphere, rather than selling itself, actually the experience makes you reluctant to leave or a desire for surprise are the goals of the experiencial marketing, and the eventually selling of the properties is just such a effective by-product of innovative thoughts, which is different form the old method that take much attention to selling buy ignore the atmosphere.

\section{The specific application of Experiential Marketing in China's Real Estate}

\subsection{Theme is the first step for leading to the experience}

Experience that economic theory, Theme is the first step for leading to the experience, and is the key step. The whole experience should be designed around a theme, in line with the theme of the meaning.

In recent years, the subject of the development of real estate propertiesfor sale has become the industry mainstream. Now the names of the properties for sale, " Sunbelt•Seaside City " "Lakeshore" As the name suggests, access to these properties for sale and you will know what the name implies. As an old Chinese saying "finishing touch", a good case is the "eyes", is the soul of the community as a whole, is the spiritual home of the banner.

And those top-level position as the theme of luxury properties for sale, often in the industry for the Great teachers, from the rare building materials, good interior decoration of the background to the design details of the individual requirements; from the construction of high quality equipment to the well - Configuration, from the landscape of rock mountains to the scarcity of copies can not be the best location. All those strive to visit the customers feeling "Who 
Make's You Feel " with the memorable experience.

\subsection{It must pay attention to customer experience sensory stimulation}

Theme is the basis of experience, and experience must also be of great importance to customers of sensory stimulation to achieve impressive. Should be to create the impression that the experience of economic theory have to make a positive impression clues to achieve harmony. For example, the theme of education to real estate, for the realization of the theme of education, developers have focused on strengthening the district's education ancillary facilities to schools with name plate.

But the impression to shaping as a whole, show only positive factor is not enough .Experience economic theory would also like to phase out negative factors. As the theme for the market to suburbanization of the real estate development, general settlement of all households, such as car transport problems in the first place, to remove the "remote location" undermine the central theme of the link.

\subsection{The guarantee of real estate marketing experiences-- Product Positioning}

In the product design process, the real estate business based on market research to study the needs of buyers in depth, can exchange views with the agents, real estate, and other planning agencies, and timely give information feedback to the product designers, in order to excavate and integrate the whole concept of the product itself to project their own different characteristic and to make them live up to the object clients' mind and spice, and finally help the clients form a certain experience.

\subsection{An important means of real estate marketing experience --Rich Humanistic Concern}

Marketing experience should stand by the consumer's position ,and from the senses, feelings, thinking and action in five areas related to redefine and to design the ways of marketing thinking.However, for real estate marketing, emotional appeals and humanistic concerns are particularly important.

\subsubsection{The productive meticulous design is the basis of experience marketing}

For residential design requirements closely "people first" idea, and integrated into the modern design philosophy and culture. First of all, in the face of different consumer groups, the control unit the size, proportion and layout, taking into account the effect of privacy.and that pay attention to the growing problem of internal functions For example, like to design self-help owners set aside some space. In addition, green building materials to be widely used to reduce pollution and improve the quality of indoor living environment.

\subsubsection{Complete Supporting Facilities and Area Environment}

Complete supporting facilities to the people is convenient, comfortable and safe experience. Real estate business not only in the pursuit of matching the number of available, but more and more emphasis on strengthening its own characteristics and realize the difference of marketing. In addition to complete supporting facilities, in recent years, what real estate business in the residential environment do is that vigorously promote the zoologizement and let people return the nature to strive to built for harmony between human, nature and architecture.

\subsubsection{Heart shape the human environment}

Humanities marketing is a very prevalent way of real estate marketing in recent years, and also is to convey a kind of experience. An increasing number of properties for sale in the marketing promotion, More and more listings in the marketing promotion, pay attention to the adoption of the demands of the humanities, such as the target consumer groups, cultural and educational facilities and the clubs' vivid description, and so on, so as to show a unique lifestyle.

\subsection{Experience scene setting}

\subsubsection{Sales offices}

Sales offices is to display real estate products and direct sales sites. Buyers expressed interest in the product and sales offices to the consultation, sales at the scene is crucial to set the scene, which will directly affect the buyers of the final purchase decision.

\subsubsection{The theme of a model room}

The theme of a model room is the combination of decorative arts and real estate sales show. It is based on the product itself characteristics and the target customer base of the features of life to design a clear example of the theme of personalized room, Design from the target bit of life experience, not the model of the structure of the units designed in accordance with the "general sense" in space. The theme of a model room is closer to target customers and real life, and thus can be caused by customer response and moved the hearts of customers.

\subsubsection{Housing Exhibition}

Fair Housing through the beautiful life-like models, the staff detailed explanation and the different characteristics 
materials, and matched to sound light, multi-angle pass to experience life to visitors.For fair housing ,there is no need for the all projects or all business signs to display on the exhibition, which key is that there is a useful selling point or a clear breakthrough to show off, so that the buyers can form a clear and unique experience.

4.6 A variety of media is a major propaganda front of marketing experience

It is needful of the experience marketing to put up the dissemination of information. The buyers receive the advertising information of real estate through newspapers, television, radio, mail, Internet, outdoor advertising, ect., but they only believe that advertising campaign of the real products, such as introduce the product with a story or a scene which can be felt. Therefore, the enterprise must strengthen to exploit experiencing elementary of products.

\section{Summary}

Marketing experience as a new marketing model, its core is active customer participation, the ultimate goal is to create a full range of experience for customers. Therefore, the real estate business customers not only from the rational point of view of consumer marketing activities, but also consider the customer's emotional consumer needs, pay attention to two-way communication with customers, develop their hearts desire, scan and improve their products and services from the perspective of the customer experience, set up a stage to show customers personality. In order to make the experiencing marketing become a important link in the process of improve the customer satisfaction and the brand loyalty.

\section{References}

B., Joseph, Pine, \& James, H.,Gilmore. (1999). The Experience Econom. Harvard Business School Press, (Chapter 2).

Bernd,H.,Schmitt. (2001). Experiential Marketing. The Free Press. New York, (15-19).

Liu, Xiangyi. (2006). Experience in real estate marketing strategy. Business Economics, (2).

Xiao, Jian. (2004). Real Estate Market - Experiential Marketing, Real Estate Business Sales.

Yao, Lixin. (2007). Real estate marketing. Chongqing University Press, Chongqing. 